\title{
LIBRE DETERMINACIÓN Y CONSULTA COMO BASES DE LOS DERECHOS FUNDAMENTALES DE LOS PUEBLOS INDÍGENAS EN LA JURISPRUDENCIA DEL SISTEMA INTERAMERICANO DE DERECHOS HUMANOS ${ }^{\delta}$
}

\author{
FREE DETERMINATION AND CONSULTATION AS A BASIS OF THE \\ FUNDAMENTAL RIGHTS OF THE INDIGENOUS PEOPLES IN THE \\ JURISPRUDENCE OF THE INTER-AMERICAN HUMAN RIGHTS SYSTEM
}

\author{
Enrique Francisco Pasillas Pineda*
}

\begin{abstract}
RESUMEN: El presente trabajo propone un análisis de los Derechos Fundamentales de los pueblos indígenas a la luz de los principios internacionales de Libre Determinación y Consulta Previa, como fundantes y presupuestos de los demás Derechos Indígenas. En consecuencia, se analiza el Derecho a la Consulta, que debe ser previa, libre, informada, de buena fe, culturalmente adecuada y con el propósito de obtener el consentimiento; donde todas éstas características son el estándar mínimo a cumplir en cualquier proyecto de desarrollo o extractivo que afecte a pueblos indígenas, por lo que debe explicarse también el extractivismo al interior de los estados-nación y su modus operandi, que ha provocado la existencia de zonas y regiones que algunos autores caracterizan como "estados de excepción" o estados de "de no-derecho". El análisis propuesto contrasta las bases mencionadas con algunos casos llevados ante la jurisdicción del Sistema Interamericano de Derechos Humanos, cuya última fase descansa en las sentencias de la Corte IDH.
\end{abstract}

\begin{abstract}
The present paper proposes an analysis of the Fundamental Rights of the indigenous peoples in the light of the international principles of Free Determination and Prior Consultation, as foundations and budgets of the other Indigenous Rights. Consequently, the Right to Consultation is analyzed, which must be prior, free, informed, in good faith, culturally appropriate and with the purpose of obtaining consent; where all these characteristics are the minimum standard to be met in any development or extractive project that affects indigenous peoples, so the extractivism within the nation-states and its modus operandi, which has caused the existence of zones and regions that some authors characterize as "states of exception" or "non-right" states. The proposed analysis contrasts the mentioned basis with some cases brought before the jurisdiction of the Inter-American Human Rights System, whose last phase rests on the judgments of the Inter-American Court.
\end{abstract}

PALABRAS CLAVE: Libre determinación y consulta, Derechos Fundamentales, pueblos indígenas

KEYWORDS: Free determination and consultation, Fundamental Rights, indigenous peoples

Fecha de recepción: 04/06/2018

Fecha de aceptación: 28/06/2018

doi: https://doi.org/10.20318/universitas.2019.4508

$\delta$ Realizado con ayuda de la Asociación Universitaria Internacional de Posgrado (AUIP) en el marco del programa del Doctorado Iberoamericano en Estudios de Paz y Conflictos (AUIP-Universidad de Granada).

* Licenciado en Derecho. Máster Oficial en Estudios Jurídicos Avanzados y Derecho Ambiental. Universidad Internacional de Andalucía. Doctorando en Ciencias Jurídicas, Universidad de Granada. E-mail: efpasillas@correo.ugr.es

Universitas, 2019, $\mathrm{N}^{\circ} 29 /$ pp. 2-31

ISSN 1698-7950 / https://doi.org/10.20318/universitas.2019.4508 


\section{1.- INTRODUCCIÓN}

Siendo el tema de los Derechos Fundamentales de los pueblos indígenas de un interés creciente en el ámbito internacional, se ha ido poniendo de relevancia de modo tal vez muy gradual en los últimos tiempos. Así, la producción normativa y jurisprudencial es relativamente reciente si se la compara con otros asuntos de Derechos Humanos, a pesar de la innegable y profunda deuda histórica de las sociedades iberoamericanas y también otras muchas del mundo, guardan para con los pueblos indígenas. Paradójicamente, el asunto de los derechos de los pueblos indígenas está volviendo a ganar importancia en el contexto de la creciente presión por la tierra y los territorios indígenas, ${ }^{1}$ causado por un modelo de "desarrollo" basado en la explotación ilimitada de los recursos naturales que algunos autores han caracterizado como un paso del llamado "consenso de Washington" al "consenso de las commodities" 2 basado en la exportación de bienes primarios a gran escala. Entre ellos, hidrocarburos (gas y petróleo), metales y minerales (cobre, oro, plata, estaño, bauxita, zinc, entre otros), productos alimenticios (maíz, soja y trigo) y biocombustibles. Este modelo, que busca sobre todo el crecimiento del producto interno bruto, se presenta frecuentemente como una oportunidad para las comunidades indígenas marginadas ${ }^{3}$, pero sus resultados - como lo 1 Para una explicación sobre tierras y territorios indígenas en el caso mexicano,
véase a F.LÓPEZ, La Tierra no se Vende, México, 2015. Sumariamente, sostiene
dicho autor que uno de los derechos fundamentales de los pueblos indígenas,
inherentes a su calidad de pueblos, es el de la libre determinación, expresado como
autonomía. Y como parte esencial de la misma, el control de su territorio y los
recursos naturales en ellos existentes. Por eso las referencias a la protección de las
tierras indígenas, la conservación y el mejoramiento de su hábitat, así como el
acceso y disfrute preferente de los recursos naturales de lugares que habitan y
ocupan, debe entenderse en su conjunto como derecho al territorio; más cuando la
legislación internacional expresa claramente que el concepto de tierra abarca el de
territorio y que éste cubre la totalidad del hábitat de las regiones que los pueblos
indígenas ocupan o utilizan de alguna manera.

2 "Utilizamos aquí el concepto de commodities en un sentido amplio, como productos indiferenciados cuyos precios se fijan internacionalmente y no requieren tecnología avanzada para su fabricación" ( $y / 0$ extracción y procesamiento). M. SVAMPA. "Extractivismo en América Latina y el consenso de las commodities", 2013. El Correo de la Diáspora Latinoamericana. Recuperado en:

http://www.elcorreo.eu.org/Extractivismo-en-America-Latina-y-el-Consenso-de-losCommodities?lang $=f r$

3 "En el caso concreto de México, no se puede pretender que las violaciones a los derechos de los pueblos indígenas fueron 'descubiertas' recientemente - al contrario, el relato de Bartolomé de las Casas: Brevísima relación de la destrucción de las Indias puede ser considerado como el primer informe sobre violaciones de derechos humanos en América Latina, si no en el mundo. Además, en el contexto mexicano, el descontento de los pueblos indígenas sobre la manera en que los gobernantes les trataron y les tratan todavía, ha sido un factor clave en dos eventos de fundamental importancia histórica, la lucha por la Independencia (181021) y la Revolución mexicana 1910-20". (J. JARAB, Los Derechos de los Pueblos 
demuestran los indicadores socio-económicos - parecen beneficiar sobre todo al sector empresarial, tanto nacional como transnacional y no a las comunidades indígenas ${ }^{4}$-que también suelen ser no indígenas-, en las que se asientan territorialmente los proyectos extractivos. De manera que cumpliéndose en 2017 el décimo aniversario de la Declaración de las Naciones Unidas sobre los Derechos de los pueblos indígenas, bien cabe preguntarse: ¿Por qué se necesitó una Declaración específica para estos grupos de personas, si en el estado nación de tradición occidental y monista somos todos libres e iguales? Hay que decirlo con claridad: es sobre todo, por la pesada y larga herencia de opresión de los pueblos indígenas en gran parte del mundo, herencia de un colonialismo racista y depredador que hasta la fecha se traduce en menosprecio y discriminación por parte de las poblaciones dominantes - y en serias dificultades para las comunidades indígenas tanto a nivel individual como colectivo, para hacer valer los derechos que las constituciones de unos estados nación más o menos democráticos y los instrumentos internacionales más o menos a su alcance, garantizan en teoría para ellos. Así es como la Declaración de la ONU sobre los Derechos de los Pueblos Indígenas no fue una nueva Convención, Tratado o Protocolo, razón por la que no fue tampoco objeto de una ratificación formal, y desde una perspectiva del positivismo jurídico bien puede ser visto como "no vinculante". Sin embargo, hay al menos tres razones fundamentales por las cuales los derechos contenidos en esta Declaración no pueden ser negados, y los pueblos y comunidades indígenas la pueden considerar como una herramienta importante en la defensa de sus Derechos Fundamentales. A saber: todos los derechos contenidos en dicha Declaración son respaldados por otros instrumentos internacionales ya ratificados por muchos estados. Segundo, porque la Declaración citada es legítima, en la medida de haber involucrado en su redacción a una gran cantidad de actores indígenas en muchos países. Tercero, porque es un instrumento con

\footnotetext{
Indígenas en México, una mirada desde el Sistema de Naciones Unidas. Oficina en México del Alto Comisionado de Naciones Unidas para los Derechos Humanos. México, Primera edición. 2018. Pág. 9.

4 "La precariedad en las condiciones de vida de la población indígena en México ha sido sistemáticamente mayor a la de la población no indígena. Aun en la actualidad, las personas que pertenecen a los pueblos originarios concentran diversos rasgos de desventaja social que las mantienen en una situación de rezago respecto al resto de la población. Muestra de ello es que, de acuerdo con las estimaciones de pobreza elaboradas por el CONEVAL, el porcentaje de población hablante de lengua indígena (HLI) que se encontraba en pobreza en 2012 casi duplicaba al de la población no hablante ( 76.8 frente a 43.0 por ciento) y el de población en pobreza extrema fue casi cinco veces mayor (38.0 frente a 7.9 por ciento)". CONSEJO NACIONAL DE EVALUACIÓN DE LA POLITIICA SOCIAL (CONEVAL). La Pobreza en la población Indígena de México 2012. Pág. 12. Recuperado en:

https://www.coneval.org.mx/Informes/Coordinacion/INFORMES_Y_PUBLICACIONE S_PDF/POBREZA_POBLACION_INDIGENA_2012.pdf
} 
largo apoyo en la comunidad internacional que fue ratificado por más de 144 países. $^{5}$

\section{2.- LIBRE DETERMINACIÓN}

Dice la citada Declaración de la ONU en su artículo 3: "Los pueblos indígenas tienen derecho a la libre determinación. En virtud de este derecho determinan libremente su condición política y persiguen libremente su desarrollo económico, social y cultural". ${ }^{6}$ Además, los artículos siguientes también hacen referencia al ejercicio de este Derecho, que es importante porque resulta ser la clave para el acceso a todos los demás, desde los económicos, sociales y culturales, hasta los civiles y políticos. Así, la Libre Determinación es el mejor camino posible para que los problemas que enfrentan los pueblos indígenas se resuelvan desde su propia visión. En este contexto, cabe mencionar la institucionalidad que debería sustentar la actuación de las diferentes autoridades públicas para respaldar el Derecho Fundamental a la libre determinación, donde en el terreno de los hechos, se precisa con urgencia de un cambio de paradigma (pasar del asistencialismo y paternalismo con pretensiones explícitas u ocultas de asimilación, al empoderamiento de estos pueblos); donde el cambio indudablemente pasa también por la manera en que las autoridades se interrelacionan con los pueblos y comunidades indígenas. ${ }^{7}$ Dos de los principios rectores de la Declaración de la ONU se traducen en la prohibición de la asimilación forzada y el Derecho a decidir sobre el propio modelo de desarrollo - y esto debería de ser el punto de partida en la relación entre las autoridades y los titulares de Derechos indígenas. Luego, ya en el discurso público, la relación entre autoridades y comunidades indígenas, o el asunto de desarrollo de estas comunidades, sigue frecuentemente identificada únicamente con la consulta o mejor dicho, con el consentimiento. Desde luego que la consulta puede y debe ser una herramienta para asegurar la implementación de los demás Derechos y también que puede ser un instrumento de empoderamiento de las comunidades indígenas.

Por lo demás, habrá de reconocerse también que dicha herramienta tiene sus limitaciones, puesto que a la vez puede ser un instrumento externo de división al interior de los pueblos y

\footnotetext{
${ }^{5}$ Aprobada en la Asamblea General de la ONU el 13 de septiembre 2007 con 144 votos a favor, 4 en contra y 11 abstenciones. Además, 6 de los países que inicialmente no apoyaron la Declaración, han revertido su posición después. (J. JARAB, Óp. Cit. Pág. 14)

6 Declaración de la ONU sobre los Derechos de Los Pueblos indígenas. Asamblea General, 13 de septiembre de 2007. En:

http://www.un.org/esa/socdev/unpfii/documents/DRIPS_es.pdf

${ }^{7}$ Véase al respecto la idea de dialogo intercultural que parte de una realidad multicultural a: E. PASILLAS, "Multiculturalismo y derechos fundamentales en el noroeste de México: El caso de la tribu yaqui", Estudios Fronterizos, Vol.19, 2018. Recuperada en: http://ref.uabc.mx/ojs/index.php/ref/article/view/658
} 
comunidades indígenas, pues no se puede endosar todos los problemas estructurales, muchas veces de décadas, a un proceso de consulta específico; pero sobre todo: a que existen realidades cada vez más complejas, donde los asuntos que afectan a los pueblos indígenas necesitan respuestas integrales. Entonces, se estima que no es factible ni deseable reducir toda relación entre autoridades y pueblos y comunidades indígenas a la mera consulta, cuando además ésta puede ser vista como un proceso instrumental o utilitario, con el objeto de validar o aprobar lo que ya se decidió, a veces a miles de kilómetros de distancia, desde un esquema "de desarrollo" vertical y autoritario que suele caracterizar a la tecnocracia. ${ }^{8}$ Entonces, hay que insistir en que no se puede obtener el consentimiento - que es el objetivo final de los procesos de consulta - sin que esta sea verdaderamente previa, libre, informada, culturalmente adecuada y de buena fe. Ya esto parece ser un desafío, porque la gran mayoría de consultas realizadas hasta hoy no fueron ni son previas. Además, había fuertes dificultades también con los demás criterios fijados por el estándar internacional de la consulta, a saber: libre, informada, de buena fe, y con el objeto de obtener el consentimiento. Es así como las autoridades tienen que reconocer y abordar también el nivel estructural que persiste y complica el contexto en el cual se desarrollan las consultas, que tiene mucho que ver con las desigualdades de poder político y económico, la secular marginación de las comunidades indígenas, así como la falta de un acceso practicable y cierto al conjunto de derechos económicos, sociales y culturales, a la poca participación política, las dificultades de acceso a la justicia, así como los riesgos vitales de las y los defensores de derechos indígenas. Las respuestas a estos desafíos no deben venir de arriba hacia abajo, sino que deben construirse desde y con los pueblos y comunidades indígenas, o aún mejor, basadas en sus propuestas y mediante un diálogo intercultural. Además, si se trata del Derecho a decidir sobre su propio modelo de desarrollo, hay que destacar que no solo aplica a los pueblos y comunidades indígenas; sino que es un principio general que ha sido reconocido ampliamente en el sistema internacional y que tiene una metodología específica basada en un "enfoque de derechos humanos en el desarrollo"9.

8 "...crecimiento típico de la receta neoliberal: gran concentración de riqueza, total
dependencia de los precios internacionales de los productos de exportación,
autoritarismo creciente ante el conflicto social causado por la extensión de la
frontera agrícola y por los megaproyectos. Aumento desordenado de la corrupción,
empezando por la élite política de gobierno." "Es sabido que el neoliberalismo, al
agravar las desigualdades sociales y generar privilegios injustos, solo se puede
mantener por la vía autoritaria y represiva." B. SANTOS, "Las venas abiertas de
Nicaragua", La Jornada, 7 de julio de 2018.
9 Se trata de una metodología que tiene dos principios claves: primero, que en todo
los proyectos, los titulares de derechos y los supuestos beneficiarios tienen que ser
involucrados en el diseño del proyecto pasando por su implementación hasta su
monitoreo y evaluación. Segundo, que en todos los proyectos de desarrollo hay que 
Dicho de manera sencilla: en el siglo XXI aprendimos que el desarrollo no se puede reducir a indicadores unidimensionales a nivel país y sobre todo, no en indicadores únicamente económicos como el PIB. ${ }^{10}$ Así, los índices de desarrollo humano, que incluyen calidad de acceso a la salud y educación, el medioambiente, alimentación, reflejan de mejor manera la realidad, a diferencia de los indicadores puramente económicos. Finalmente, en esta alusión de actores clave, merece la pena mencionar otro actor fundamental: las empresas. Esto porque en una interpretación estricta de Derechos Humanos basada en las personas como entes físicos individuales como titulares de derechos y obligaciones, no existe un instrumento vinculatorio para las personas jurídicas, pero sin embargo existen los principios rectores de la ONU sobre empresas y Derechos Humanos ${ }^{11}$ que cada día pueden ser mejor conocidos y aceptados por las empresas, hasta el punto de que son muy pocas las que declaran públicamente que no quieren respetar principios como el de la "debida diligencia", por ejemplo. ${ }^{12}$ En suma, es importante destacar que se precisa de un diálogo intercultural que pase por intentar entender y escuchar al

asegurar un enfoque particular a los grupos que están en mayor situación de vulnerabilidad para evitar que los que tradicionalmente han sido marginados se queden fuera de los beneficios o sufran consecuencias negativas (J. JARAB, Op. Cit. Pág.19).

10 Dicho enfoque refleja una nueva postura en la agenda general de Naciones Unidas: la llamada "Agenda 2030" con sus objetivos de desarrollo sostenible, que no es sólo ambiental; porque si bien es importante reducir la tala de bosques y evitar la deforestación masiva o la contaminación del medioambiente y el agua, también tenemos que dar importancia a la sustentabilidad social, cultural y otras. La agenda 2030 también representa un cambio comparado con los llamados "objetivos de desarrollo del milenio", los cuales se enfocaron en mejorar algunos indicadores -sin duda importantes- a nivel de un país entero, con un esquema de países de ingreso medio o países en desarrollo. Pero el nuevo enfoque es mucho más orientado hacia desigualdades dentro de las propias sociedades, con el lema central de "no dejar a nadie atrás", lo que refleja el reconocimiento de que el desarrollo tradicional frecuentemente tuvo efectos positivos en lo macro, pero fortaleció brechas y desigualdades dentro de las sociedades (J. JARAB, Cit. PP.: 1926).

${ }^{11}$ ONU, Principios Rectores sobre las Empresas y los Derechos Humanos. Puesta en práctica del marco de las Naciones Unidas para "proteger, respetar y remediar". Nueva York y Ginebra. 2011. Recuperado en:

http://www.ohchr.org/Documents/Publications/GuidingPrinciplesBusinessHR_SP.pdf 12 Además, cabe mencionar el reciente Comentario General número 24 del Comité de Derechos Económicos, Sociales y Culturales de la ONU, que explica que los países, para cumplir con sus deberes de respetar, proteger y promover estos derechos, tienen la obligación de regular el actuar del sector empresarial. (Naciones Unidas. Consejo Económico y Social. Comité de Derechos Económicos, Sociales y culturales. Observación general núm. 24 (2017) sobre las obligaciones delos Estados en virtud del Pacto Internacional de Derechos Económicos, Sociales y Culturales en el contexto de las actividades empresariales. Aprobada por el Comité de Derechos Económicos, Sociales y Culturales en su $61^{\text {er }}$ período de sesiones (29 de mayo a 23 de junio de 2017). Recuperado en:

https://tbinternet.ohchr.org/_layouts/treatybodyexternal/TBSearch.aspx?Lang=en\& TreatyID $=9 \&$ DocTypeID $=11$ ) 
otro. Partiendo de allí, realizar propuestas en común como parte de la construcción de una política de estado transversal, unas relaciones institucionales y un marco jurídico plural. Ciertamente que aparecen muchas dificultades en un diálogo intercultural, pero aun así parece el mejor camino a seguir, pues cualquiera de las otras alternativas disponibles para instituciones políticas y pueblos indígenas, parecen inaceptables en un estado democrático, social y de Derecho.

\section{3.- CONSULTA PREVIA}

Es dudoso que los avances en las normas y políticas nacionales e internacionales hayan avanzado al mismo ritmo que las realidades que enfrentan día a día los pueblos indígenas para exigir y garantizar derechos tan importantes como su auto-adscripción, el Derecho a sus territorios, o el Derecho a su cultura y conocimientos ancestrales. $Y$ es ahí donde el derecho a la consulta y el consentimiento previo, libre e informado adquiere especial relevancia, pues si bien no es un derecho sustantivo, sí que es una herramienta que lleva a la implementación de los otros derechos que sí son sustantivos, pues genera un equilibrio en el diálogo y la participación que permite identificar riesgos y generar acuerdos, pero sólo cuando es implementada de forma adecuada. Así, la consulta previa, libre, informada y de buena fe no puede ser tenida como un trámite más para cumplir con una lista, ni tampoco es un mero requisito formal. La consulta representa entonces una oportunidad real de generar confianza entre partes con contextos e intereses diferentes para buscar un escenario en el que todas puedan verse beneficiadas. ${ }^{13}$ Así, el hecho de que los gobiernos de los diferentes estados-nación reconozcan y asuman la obligación de realizar estas consultas es un paso positivo y merece reconocimiento. Sin embargo, aún existen muchos aspectos urgentes para fortalecer el adecuado cumplimiento de este Derecho Fundamental de los pueblos indígenas que resulta además en una clara obligación internacional para los Estadosnación. ${ }^{14}$

\footnotetext{
${ }^{13}$ Y resulta oportuna, dado el considerable aumento de consultas en todo el mundo, como las que se ha visto obligado a asumir el gobierno mexicano desde la paradigmática aunque inefectiva sentencia de la Suprema Corte de Justicia de la Nación en 2013, relacionada con el caso de la tribu Yaqui. Véase respecto de éste caso a: E. PASILLAS, Op. cit.

14 "Nuestra Oficina ha documentado varios procesos de consulta en la república, incluyendo proyectos que afectaron los derechos de las comunidades zapotecas en Oaxaca, de los yaquis en Sonora, de los otomís en el Estado de México y Puebla, o de los mayas en Campeche, entre otros. Algunos de estos casos cuentan con recomendaciones de la CNDH o con sentencias judiciales, incluso de la SCJN. En todos estos procesos, hemos podido documentar ciertos patrones de dificultades relacionadas al dialogo intercultural y los problemas que pueden surgir 0 exacerbarse si los procesos no son implementados de manera correcta. Sobre todo, hemos observado los efectos de contraproducentes que resultan si la consulta padece de buena fe o tiene como efecto u objetivo dividir a las comunidades
} 
De manera que es necesario evitar que la consulta se usada de mala fe, y que en lugar de abrir espacios de diálogo intercultural, resulte en la fragmentación de las comunidades indígenas y en un aumento de conflictos entre y adentro de ellas. Así, la correcta interpretación y aplicación de los diferentes criterios relacionados a los procesos de consulta es fundamental y los requisitos de que sean previas, libres, informadas, culturalmente adecuada y de buena fe, responden a una lógica que podrá analizarse a detalle en los siguientes apartados.

\section{4.- DERECHO A LA CONSULTA PREVIA EN LOS (MEGA) PROYECTOS DE INVERSIÓN}

Sería imposible en 2018 hablar del Derecho a la Consulta y a la Libre Determinación de los pueblos indígenas sin explicar un fenómeno que les es consustancial, la denominada "acumulación por desposesión", término acuñado por David Harvey, ${ }^{15}$ así como del extractivismo y el nuevo extractivismo. $Y$ al respecto podemos decir primeramente, que es muy sencillo comprobar con un poco de curiosidad que el término "extractivismo" ni siquiera aparece consignando en los diccionarios de lengua española. En el de la Real Academia, por ejemplo (www.rae.es). Entonces, para intentar delimitar el término, podríamos decir de una manera simple que el extractivismo, en este marco general del "sistema-mundo" caracterizado por Wallerstein ${ }^{16}$ entre otros autores relevantes, es "una forma de organizar la economía de un país, basada en una alta dependencia de la extracción intensiva (en grandes volúmenes) de recursos naturales con muy bajo procesamiento y valor agregado y destinado para su venta en el exterior (exportación); donde los rasgos principales de esas economías son su alta dependencia de la extracción de recursos naturales, por una parte. $Y$ por otra, la extracción en grandes volúmenes de esos mismos recursos con un bajo procesamiento o escaso valor agregado; donde son extraídos para su venta en el exterior. En otras palabras, el término "extractivismo" proviene básicamente de la palabra "extracción": es decir, que se elimina un recurso natural (minerales, petróleo, agricultura, ganadería, silvicultura, etc.) de su entorno y luego se vende en el mercado, por lo general internacional. El Estado, a través del cobro de tarifas o del denominado "efecto de goteo" hacia abajo, se sirve de este modelo a pesar de que no necesariamente es el actor

indígenas o de exacerbar las divisiones y tensiones internas que ya existen" ( $\mathrm{J}$. JARAB, J. Cit. Pág. 26).

15 D. HARVEY, El "nuevo" Imperialismo: Acumulación por desposesión. CLACSO, Buenos Aires. 2005.

${ }^{16}$ I.WALLERSTEIN, "El Multiculturalismo y sus Dilemas", La Jornada, 22 de febrero de 2015. Recuperado en:

http://www.jornada.unam.mx/2015/02/22/opinion/022a1mun 
central en la actividad extractiva. Así, la economía de un país parece ganar, porque el Producto Interno Bruto (PIB) crece gradualmente a medida que los recursos no explotados anteriormente se integran en el proceso económico. ${ }^{17}$ Pero en un sentido más amplio, usaremos el término "extractivismo" cuando nos refiramos a aquellas actividades que remueven grandes volúmenes de recursos naturales que no son procesados (o que lo son limitadamente), sobre todo para la exportación. Aunque como se ha mencionado, el extractivismo no se limita solo a los minerales o al petróleo. Hay también extractivismo urbano, agrario, forestal e inclusive pesquero. ${ }^{18}$ Entonces, los países del denominado "sur global", estarían atrapados en una lógica perversa conocida en la literatura especializada como "la paradoja de la abundancia" o "la maldición de los recursos naturales". En este contexto, incluso hay quienes han asumido esta condición (casi) como un "fatalismo tropical": Por ejemplo, El Banco Interamericano de Desarrollo (BID) ha defendido en varios de sus reportes anuales y estudios técnicos "un determinismo geográfico del desarrollo: los países más ricos en recursos naturales y más cercanos al Ecuador (a la línea ecuatorial) están condenados a ser más atrasados y pobres. (...) Es decir que a juicio del BID, cuanto más rico sea un país en recursos naturales, más lento será su desarrollo y mayores sus desigualdades internas". ${ }^{19}$ Dice también Harvey en su libro Seventeen Contradictions and the End of Capitalism (Traducido como: Diecisiete contradicciones y el fin del Capitalismo) a propósito del capitalismo que sostiene el modelo extractivo -en el que se fincan los denominados proyectos o mega proyectos de inversión, también llamados de "desarrollo"-; que el capitalismo requiere de crisis constantes para su expansión. ${ }^{20}$ Son las mismas crisis del sistemamundo observadas por autores como Wallerstein ${ }^{21}$, Martínez Alier ${ }^{22} 0$ Toledo, 23 donde dichos autores sostienen que "otros mundos" se están construyendo de manera silenciosa y a contracorriente del modelo dominante centro-periferia y norte-sur (V.TOLEDO, Óp. Cit).

17 S.TREMBLAY y G. HÉBERT, "¿Que es el extractivismo?" Martes 26 de febrero. 2013. Recuperado en:

http://www.conflictosmineros.net/contenidos/18-internacional/12097-ique-esextractivismo.

18 A. ACOSTA, "Extractivismo y neoextractivismo, dos caras de la misma maldición", 25 de julio. 2012. Recuperado en: ecoportal.net.

19 E. GUDYNAS, "La ecología política de la crisis global y los límites del capitalismo benévolo", Iconos, Revista de Ciencias Sociales, No 36, Quito, enero de 2010.

20 D.HARVEY, Seventeen contradictions and the end of capitalism, Oxford University Press. 2015.

${ }^{21}$ I. WALLERSTEIN, Op.cit.

22 J. MARTÍNEZ "Ecología política del extractivismo y justicia socio-ambiental". Interdisciplina, Vol. 3, No.7, UNAM. 2015. Recuperado en:

http://www.revistas.unam.mx/index.php/inter/article/view/52384

23 V. TOLEDO, "Las Luchas Territoriales anuncian un cambio civilizatorio", La Jornada, 11 de octubre, 2016. Recuperado en:

http://www.jornada.unam.mx/2016/10/11/opinion/018a1pol 
Así, tal vez sea necesario reconocer que el mundo se enfrenta a una crisis que se ha dado en llamar "civilizatoria" y que, por tanto, se requiere también de una transformación en ese sentido. Ello supone un cuestionamiento radical y profundo de los principales paradigmas de la civilización moderna e industrial: el petróleo, el capitalismo, la ciencia, los partidos políticos, los bancos, las corporaciones multinacionales o la democracia representativa, así como el Derecho o el consumismo, pues como lo interpreta Boaventura de Sousa Santos: "No hay solución moderna a la crisis de la modernidad". 24 Vivimos entonces una época caracterizada por la mayor concentración de la riqueza en la historia de la humanidad, donde visto a priori, el capital ha terminado por devorar al Estado. ${ }^{25}$ Así, los límites entre el poder económico y el poder político se han diluido o se han borrado, y se ha vuelto entonces virtualmente imposible, mediante la vía denominada "democrática", lograr los cambios profundos que el mundo requiere con urgencia y que deben superar dos limitantes supremas de la modernidad: la mayor desigualdad social de que se tenga memoria y el mayor desequilibrio ambiental a escala planetaria, donde los ciudadanos y su poder van quedando anulados. La sociedad moderna ha perdido entonces su capacidad de auto transformación y con ello sus mecanismos de autocorrección, en un contexto donde la crisis ambiental amenaza ya la supervivencia humana en el futuro inmediato. Así, la democracia representativa, principal aportación de occidente al mundo, se ha convertido en mera ilusión (V.TOLEDO, Óp. Cit).

Por otra parte, hay que señalar que la idea detrás de los términos "acumulación por desposesión" fue acuñada originariamente por David Harvey en: "The new imperialism", traducido al español como: "El "Nuevo" Imperialismo: Acumulación por Desposesión"26. Donde Harvey lo expresa claramente desde sus primeras páginas: "all about oil", o casi. Después, en tiempos de crisis del capitalismo global y su impacto sobre el precio de las materias primas o commodities que exportan casi todos los países de la región Iberoamericana, basados en la exportación de bienes primarios a gran escala:

24 V. TOLEDO. "La Crisis de la Modernidad requiere una transformación civilizatoria". Memoria, Revista de Crítica Militante. 2018. Recuperado en: https://revistamemoria. $\mathrm{mx} / \mathrm{p} \mathrm{p}=1239$

25 "El neoliberalismo no es sólo una política económica. No se reduce a un programa de gobierno. El neoliberalismo es una manera de entender el mundo, una ideología en el sentido más fuerte de la palabra, que implica una idea de la sociedad, una idea del derecho, de la educación, de los vínculos humanos, una idea de la justicia y de la naturaleza humana. No es obra de un individuo ni de un pequeño grupo, sino de varias generaciones de filósofos, economistas, sociólogos, juristas..." F. ESCALANTE, Historia Mínima del Neoliberalismo, El Colegio de México, México. 2015.

26 D. HARVEY, El "nuevo" imperialismo: acumulación por desposesión, El Nuevo desafío Imperial, Pantich Leo y Colin Leys (ed.) Merlin Press-CLACSO. Buenos Aires. 2005. 
hidrocarburos (gas y petróleo), metales y minerales (cobre, oro, plata, estaño, bauxita, zinc, entre otros), productos alimenticios (maíz, soja y trigo) y biocombustibles (M. SVAMPA, Óp. Cit.). Se puede apreciar que es una de las causas que explican el aceleramiento y agudización del fenómeno extractivo en el sistemamundo descrito por I. Wallerstein, Toledo, o J. Martínez, 27 Dicho lo anterior, es sin embargo pertinente aclarar que hasta donde podemos conocer por el momento, ni el extractivismo ni el capitalismo son en sí mismos modelos económicos, pues aunque discutir la índole precisa del capitalismo ${ }^{28}$ escapa al marco y pretensiones del presente trabajo, digamos por lo pronto que el extractivismo, al parecer inherente al capitalismo, no parece ser es en sí mismo un modelo, sino un entramado que desde luego comprende a la economía, pero que va más allá de ella, a las leyes y al Derecho, por ejemplo, donde bien podría ser considerado como la "fase más actual" del capitalismo. Por lo tanto, no podemos aislar lo económico del conjunto del "sistema-mundo". Esto importa resaltarlo porque la derrota cultural que implicó la caída del 'socialismo real' parece conducirnos a que en nuestros días la economía y las leyes del mercado lo son todo. Sabemos, claro, que la economía es una parte muy importante del sistema en el que vivimos, aunque el sistema en que vivimos no puede ni debe reducirse solo a su variante económica. ${ }^{29}$ Por otra parte, el análisis del extractivismo ha sido y sigue siendo hasta hoy parcial e incompleto. Hace 10 o 15 años, cuando se relanzó el tema de las llamadas commodities a propósito de la minería en algunos países del sur global; la agricultura en otros, dejamos de lado la comprensión de que el extractivismo también es

\footnotetext{
27 Se supone entonces que no solo estalla y se extiende la "crisis", sino además se da una utilización capitalista de ella, misma que es protagonizada por las trasnacionales y el capital financiero. Por ejemplo, para rebajar el coste global de la fuerza de trabajo mediante las devaluaciones, la inflación o la eliminación evidente o soterrada de los salarios indirectos (jubilaciones, pensiones, indemnizaciones, subsidios, sanidad y educación públicas), donde se requiere de la existencia de gobiernos afines, autoritarios o bien de abiertas dictaduras para imponer a las poblaciones las medidas de "ajuste" necesarias. Hablamos aquí en general de democracias opacas y de gobiernos corruptos, proclives a hacer "el trabajo sucio" que precisan las multinacionales para profundizar el modelo extractivo.

28 Recientemente, Thomas Piketty, profesor de la Ecole de Economie de Paris, en su libro El Capital en el Siglo XXI, señala que cada nación ha respondido de modo distinto a una ley básica del capitalismo, según la cual el rendimiento del capital suele ser superior a veces por mucho, a la tasa de crecimiento de la economía, lo que puede estimular la concentración de la riqueza y agravar la inequidad. Queda entonces en los estados decidir, colectivamente, se entiende, como influir en esa fuerza polarizante. Por eso propone introducir políticas fiscales de alcance global que moderen la disparidad, como los impuestos a la riqueza y a las herencias, imponer impuestos progresivos sobre el ingreso, y reducción del déficit y la deuda pública, para modernizar un estado que se necesita que sea social, pero en ningún caso desmantelarlo, como se ha venido haciendo durante las últimas décadas.

29 R. ZIBECHI, Latiendo Resistencia. Mundos Nuevos y Guerras de Despojo, El Rebozo, Oaxaca, 2015.
} 
un fenómeno global, no solo del sur del sistema-mundo. Urbano, por ejemplo, porque la especulación inmobiliaria urbana es parte integral también del modelo extractivista. Observando las lógicas y consecuencias de la llamada "mega" minería, de la expansión del monocultivo sojero, o la explotación de hidrocarburos no convencionales, se han encontrado rasgos de gran similitud respecto de los efectos y características de la especulación inmobiliaria y la entrega del suelo urbano para la expansión del capital en contextos urbanos. ${ }^{3031}$ Todo lo anterior lo hemos ido comprendiendo progresivamente, viendo los efectos ambientales o en la salud de las poblaciones a nivel de enfermedades crónicas o degenerativas como posibles efectos del modelo. ${ }^{32}$ Entonces, el extractivismo incluye, como dice Harvey: una "acumulación por desposesión" (es decir, acumulación por despojo o por robo. Pero aún esto es insuficiente, ya que no se reduce a ello). En el caso concreto de Iberoamérica o de México; si se atiende a los más de 300 conflictos socio-ambientales documentados (V.TOLEDO, Óp. Cit.). Coincidente con los hallazgos de Martínez Alier (J. MARTÍNEZ, Op. Cit.) O al informe que un grupo de Organizaciones de la Sociedad Civil en México presentaron el 2016 a una relatoría especial de la ONU que revisa la responsabilidad de las empresas en el respeto a los Derechos Humanos de las personas. ${ }^{3334}$

30 Véase por ejemplo a: A.VÁSQUEZ (comp) Extractivismo urbano, Debates para una construcción Colectiva de Ciudades, Colección Chico Mendes, Editorial El Colectivo, CEAPI-Fundación Rosa de Luxemburgo, Buenos Aires. 2017.

31 "A partir de este análisis, el concepto de extractivismo urbano busca aportar una nueva matriz explicativa que permita atender a las problemáticas y las desigualdades en las ciudades, no como elementos aislados entre sí, sino como resultado de un modelo de desarrollo determinado y planificado. Pensar los contextos urbanos en la clave del extractivismo nos abre la posibilidad de ver fenómenos concretos bajo la lupa del modelo económico-financiero que las sostiene y produce" (VIALE, E. en A.VÁSQUEZ, Op. Cit. Pág. 9).

32 Obesidad, diabetes o cáncer en niveles desconocidos hasta ahora en amplios sectores de la población mundial, así como un dilatado catálogo de enfermedades crónicas y crónico-degenerativas. Por ejemplo, la población de México está en el segundo lugar mundial en obesidad, y en el primero en diabetes melitus según informaciones de la OMS ("Emite la Secretaría de Salud emergencia epidemiológica por diabetes mellitus y obesidad", https://www.gob.mx/salud/prensa/emite-lasecretaria-de-salud-emergencia-epidemiologica-por-diabetes-mellitus-y-obesidad).

33 Compendio de información presentado por la coalición de organizaciones de la Sociedad Civil al grupo de Trabajo sobre empresas y Derechos Humanos de la ONU. En dicho informe, llamado México: empresas y derechos humanos, (2016) se indica que los principales abusos cometidos son la falta de consulta previa, libre, informada y culturalmente adecuada, de debida diligencia y la proliferación de megaproyectos. Empresas trasnacionales y nacionales han quedado evidenciadas ante la Organización de las Naciones Unidas (ONU) por violación a los derechos humanos. El listado de más de 60 casos de violaciones a derechos humanos fue presentado por organizaciones no gubernamentales ante un equipo de trabajo del organismo internacional. Las compañías denunciadas son 99: 41 nacionales, 50 extranjeras y 8 del Estado. Entre las involucradas destacan Grupo Higa, Tradeco, Bimbo, Cargill, Monsanto, Grupo Carso y Grupo Bal, Grupo México, Minera Excellon, Petróleos Mexicanos. El documento, elaborado por más de 100 organizaciones 


\section{5.- CARACTERÍSTICAS DEL EXTRACTIVISMO}

Entonces, es cierto que los conflictos socio-ambientales y las luchas por el territorio que caracterizan Toledo o Martínez Alier ${ }^{35}$ se multiplicaron en los pasados años por todo el mundo como una reacción popular ante la devastación producida por los megaproyectos extractivos, impulsados por una más o menos clara complicidad (dependiendo del caso en concreto) entre gobiernos corruptos encaramados al Estado, por una parte, y el capital transnacional por la otra. Minería, petróleo, o agroindustria. Pero también turismo, especulación inmobiliaria y urbana, proyectos carreteros, de represas o biotecnológicos. ${ }^{36} \mathrm{Y}$ no solo eso. Sabemos por diversos estudios antropológicos que el territorio es una de las dimensiones individuales donde se reproduce el ser y la memoria biocultural del hombre. Así, la defensa del territorio que hacen muchos pueblos originarios amenazados es una defensa de la vida. Y también es una lucha epistemológica para autores como Santos ${ }^{37}$ u ontológica, como lo es para Escobar, que coincide en señalar, como los zapatistas, que son luchas por un mundo donde quepan muchos

defensoras de Derechos Humanos (entre ellas Centro de Derechos Humanos Miguel Agustín Pro Juárez, Centro Mexicano de Derecho Ambiental, Fundar Centro de Análisis e Investigación, Greenpeace México, Oxfam México, Serapaz, Servicios y Asesoría para la Paz, Proyecto de Derechos Económicos, Sociales y Culturales), precisa los casos de abuso a derechos humanos relacionados con actividades empresariales como minería (11), cementeras (5), hidrocarburos (9); producción de energía mediante hidroeléctricas y parques eólicos y abusos relacionados con los consumidores (8); construcción de infraestructura (9); agroindustria y forestal (6); maquilas y corredores industriales (4), y otras ramas productivas (8), además de empresas de seguridad privada, exportación ilegal de arma a zonas de conflicto y turismo.

34 Movimientos sociales que son actores relevantes, como los indígenas zapatistas de Chiapas, sostienen que hay guerras de distinta índole en curso en el sistemamundo, y que en algunos lugares se ve claramente: en Siria o en Irak, por ejemplo, pero también en Asia y África. Son guerras, sostienen, contra los pueblos para apropiarse de los bienes comunes, los más importantes: la energía, el agua y la tierra. En otros lugares, las guerras no son abiertas, sino soterradas, como bien puede ser el patrón de despojo de recursos naturales que sufren los pueblos indígenas de las Américas.

35 UNIVERSITAT AUTONOMA DE BARCELONA UAB. El EJAtlas alcanza los 2.100 casos de estudio de conflictos socio-ambientales en el mundo, 2017. El Atlas de Justicia Ambiental (EJAtlas), creado por investigadores del Institut de Ciència $i$ Tecnologia Ambientals de la Universitat Autònoma de Barcelona (ICTA-UAB), cuenta en la actualidad con 2.100 casos de conflictos ecológico-distributivos identificados en distintas partes del mundo. 3 de mayo. 2017. Recuperado en:

http://www.uab.cat/web/sala-de-prensa/detalle-noticia/el-ejatlas-alcanza-los-2100-casos-de-estudio-de-conflictos-socio-ambientales-en-el-mundo1345667994339. html?noticiaid $=1345724763308$.

${ }^{36}$ El caso de la soya transgénica es paradigmático, como describe Vandana Shiva en el libro Cosecha Robada. El secuestro del suministro mundial de alimentos, 2003.

37 B. SANTOS, Pensar el Estado y La Sociedad: Desafíos actuales, CLACSO coediciones, Waldhuter Editores, Buenos Aires, 2009. 
mundos, es decir, por un "pluriverso". 38 Pero es que además estos conflictos socio-ambientales cimbran el fundamento mismo del Estado-Nación, al introducir de nuevo al debate público el tema de la diversidad de los espacios. ${ }^{39}$ Así, el fin último de las resistencias territoriales es re-significar los Derechos a la vida, a la autogestión, la autosuficiencia y la autodefensa. 40 Justamente por eso se atisban en los años que vendrán movimientos autonómicos regionales de matriz indígena $\mathrm{y} / \mathrm{o}$ territorial en muchos países de Iberoamérica $\mathrm{y}$ probablemente también del resto del mundo. De manera que en el futuro tal vez veamos naciones y países basados en la identidad cultural. A esta nueva realidad que llega Toledo la llama: "cambio civilizatorio"41. Decimos entonces que hay que considerar al extractivismo como una (re) actualización modificada del hecho histórico denominado "colonial". En esta dirección, se apuntan unas características del extractivismo, ${ }^{42}$ que sistematizan diversos aportes: en primer lugar, el extractivismo implica una ocupación del territorio, ya sea a través de los monocultivos, la minería, los hidrocarburos, la agroindustria, la pesca, o la especulación inmobiliaria. En segundo lugar, se establecen relaciones asimétricas entre las grandes empresas, sean nacionales o transnacionales y los Estados y las poblaciones, donde generalmente los estados y gobiernos no toman

38 A. ESCOBAR, "Más allá del desarrollo: postdesarrollo y transiciones hacia el pluriverso", Revista de Antropología Social, 2012, 21 pp. 23-62, 2012. Recuperado en: https://revistas.ucm.es/index.php/RASO/article/viewFile/40049/38479

39 "Todo país en es menor o mayor medida un complejo mosaico de comarcas, regiones, municipios, merindades, provincias, cada uno con un contenido biocultural e identitario donde los pueblos poseen maneras particulares de pensar y de actuar, que resisten la uniformación en tiempos donde al parecer la modernidad intenta aplastar toda manifestación de alteridad o diferencia. Por ello los Estadosnación son entidades de existencia insostenible" (V.TOLEDO, Op. Cit.).

${ }^{40}$ Como lo demuestra significativamente en el caso mexicano, el municipio indígena purépecha de Cherán-Keri, en la meseta de Michoacán. Véase al respecto a: $P$. PÉREZ, "El Gobierno autónomo Indígena de Cherán-K éri, Michoacán, México." Revista FAIA - Programa Internacional de Investigación en Filosofía Intercultural de la Liberación. ISSN 2250-6810. Buenos Aires. En:

http://editorialabiertafaia.com/pifilojs/index.php/FAIA/article/view/129

41 V.TOLEDO, Op. Cit.

42 "En la última década el extractivismo se ha profundizado en prácticamente todos los países de la región, incluyendo y destacándose a la vez los países donde en el mismo tiempo se han encumbrado regímenes progresistas, pretendidamente antineoliberales. Las exportaciones de Bolivia, Argentina, Brasil, Venezuela, Perú y Ecuador, entre otros, se concentran en pocos recursos naturales que al cabo del ciclo de precios elevados, cada uno de los países tendrá severos problemas económicos incluyendo la dependencia fiscal a los ingresos de los recursos exportados y el encarecimiento de bienes importados, lo cual es una condición típica de los países mono productores de materias primas. Los problemas económicos, sociales, políticos y ambientales de esta escalada extractivista se multiplican y en muchos casos son de tal envergadura que no pueden ser atendidos por los gobiernos que sólo atinan a reprimir y criminalizar a la oposición social, tildándola de eco-terrorista" (M. GANDARILLAS, (Ed). Extractivismo, nuevos contextos de dominación y resistencia. CEDIB. Cochabamba, Bolivia. Pág. 5, 2014).

Universitas, 2019, $\mathrm{N}^{\circ} 29 /$ pp. 2-31 
posiciones imparciales, como se aprecia claramente en muchos de los casos emblemáticos. En tercer lugar, el extractivismo ha generado economías de "enclave", 43 como en el periodo colonial: economías de enclave que son como islas que no derraman riqueza sobre la población, sino que son economías autárquicas o volcadas hacia el exterior. En cuarto lugar, se registran intervenciones políticas de las empresas, en no pocas ocasiones aliadas con los gobiernos para modificar leyes, cooptar actores sociales y políticos, instituciones y Estados por entero. En quinto lugar, el extractivismo es un ataque frontal a la agricultura familiar porque destruye la soberanía alimentaria $^{44,45}$ de los pueblos ${ }^{46}$ al atacar directamente a la

${ }^{43}$ En economía, se dice que un "enclave" evoca una actividad económica desligada de los otros sectores productivos. Los enclaves tradicionales generalmente eran enclaves mineros, petroleros, plantaciones tropicales o agro-negocios, productores de materias primas, intensivos en insumos importados para la posterior elaboración y consumo de materias primas en países capitalistas desarrollados. En cambio, en el "nuevo" modelo de enclave presentado, lo que proviene del exterior, modela su territorio de implantación. El concepto de enclave es un modo social de producción, no es aisladamente geográfico ni económico, sino económico, geográfico y social a la vez, mantiene plena actualidad pero necesita ser adaptado" (D. CADEMARTORI. Inversión extranjera en el desarrollo de la región minera de Antofagasta (Chile): historia y perspectivas, Edición electrónica gratuita. Pp. 21-23. 2010. Texto completo en: www.eumed.net/libros/2010b/677/)

44 "Existe seguridad alimentaria cuando todas las personas tienen, en todo momento, acceso físico y económico a suficientes alimentos, inocuos y nutritivos para satisfacer sus necesidades alimenticias y sus preferencias en cuanto a los alimentos, a fin de llevar una vida activa y sana". Esta definición le otorga una mayor fuerza a la índole multidimensional de la seguridad alimentaria e incluye "la disponibilidad de alimentos, el acceso a los alimentos, la utilización biológica de los alimentos y la estabilidad [de los otros tres elementos a lo largo del tiempo]" (FAO, 2006). La FAO había reafirmado también que "un entorno político, social y económico pacífico, estable y propicio, constituye la base fundamental que permitirá a los Estados atribuir la debida prioridad a la seguridad alimentaria y la erradicación de la pobreza. La democracia, la promoción y protección de todos los derechos humanos y libertades fundamentales, inclusive el derecho al desarrollo, y la participación plena y equitativa de hombres y mujeres son indispensables, a fin de alcanzar la seguridad alimentaria sostenible para todos" (FAO, 1996). De acuerdo con The Six Pillars of Food Sovereignty, developed at Nyéléni, 2007 (Food Secure Canada, 2012), la soberanía alimentaria descansa sobre seis pilares: 1.Se centra en alimentos para los pueblos: a) Pone la necesidad de alimentación de las personas en el centro de las políticas. b) Insiste en que la comida es algo más que una mercancía. 2. Pone en valor a los proveedores de alimentos: a) Apoya modos de vida sostenibles. b) Respeta el trabajo de todos los proveedores de alimentos. 3. Localiza los sistemas alimentarios: a) Reduce la distancia entre proveedores y consumidores de alimentos. b) Rechaza el dumping y la asistencia alimentaria inapropiada. c) Resiste la dependencia de corporaciones remotas e irresponsables. 4. Sitúa el control a nivel local: a) Lugares de control están en manos de proveedores locales de alimentos. b) Reconoce la necesidad de habitar y compartir territorios. c) Rechaza la privatización de los recursos naturales. 5. Promueve el conocimiento y las habilidades: a) Se basa en los conocimientos tradicionales. b) Utiliza la investigación para apoyar y transmitir este conocimiento a generaciones futuras. c) Rechaza las tecnologías que atentan contra los sistemas alimentarios locales. 6. Es compatible con la naturaleza: a) Maximiza las contribuciones de los 
agricultura familiar. ${ }^{47}$ La sexta característica es la militarización de los territorios. Y por último, entendemos que el extractivismo es un actor total y no solo económico, porque elige o hace elegir a los parlamentos, presidentes, gobernadores o alcaldes que más le

ecosistemas. b) mejora la capacidad de recuperación. c) Rechaza el uso intensivo de energías de monocultivo industrializado y demás métodos destructivos". G. GORDILLO, Seguridad y Soberanía alimentarias. Documento base para discusión. Organización de las Naciones Unidas para la Alimentación y la Agricultura, (FAO). 2013. Recuperado en: http://www.fao.org/3/a-ax736s.pdf)

45 Por ejemplo, se sabe que México es uno de los países que mayor dependencia alimentaria tienen por lo que compran al exterior: "México es el séptimo mercado de alimentos en el mundo con un estimado de 903 mil millones de pesos al año, pero 18.3 por ciento de la población se encuentra en algún grado de carencia alimentaria y 16 por ciento está en situación de riesgo alimentario permanente." (CONEVAL, 2013); cuando paradójicamente es al mismo tiempo uno de los países con una potente agroindustria de monocultivos de exportación. Véase por ejemplo a González: "analizo las implicaciones que ha tenido el desarrollo de la producción intensiva de frutas y hortalizas en México para el mercado mundial sobre la degradación ambiental y el deterioro de la salud de los trabajadores y de los habitantes de las áreas de cultivo. Mi tesis es que para entender en su complejidad la "insustentabilidad" de esta agricultura es necesario analizarla en la totalidad de las relaciones que establecen los actores sociales que participan en la producción, la distribución y el consumo de estas mercancías; esto es, en la cadena global de ellas." H. GONZÁLEZ, "Las redes transnacionales y las cadenas globales de mercancías: la agricultura de exportación en México", Amérique Latine Histoire et Mémoire. Les Cahiers ALHIM [En línea], 2|2001, Publicado el 13 enero 2006, consultado el 19 mayo 2018. URL: http://journals.openedition.org/alhim/613

46 "La epidemia de sobrepeso y obesidad que asola al país es consecuencia del modelo de dependencia alimentaria, abandono del campo y entrega de las decisiones de política pública en materia de agricultura y alimentación a las llamadas "fuerzas del mercado", al "libre mercado" y, en los hechos, a los intereses externos y a los monopolios. A lo largo de tres décadas de dependencia alimentaria se ha desmantelado la capacidad del país para producir sus propios alimentos, a favor de las importaciones y de las corporaciones agroalimentarias nacionales y extranjeras, provocando una competencia desleal a los productores nacionales, una caída en la rentabilidad y un crecimiento sostenido en la pobreza, migración, deterioro del entorno natural, carestía, hambre, desnutrición, obesidad y sobrepeso. Nuestro país sufre una condición de inseguridad y vulnerabilidad alimentaria sin precedentes, que compromete seriamente la soberanía nacional y afecta gravemente nuestros derechos y la salud alimentaria de la gran mayoría de la población nacional. Importamos más del $40 \%$ de los alimentos que consumimos en el país. De no cambiar la tendencia observada desde 1982 a la fecha, de acuerdo con el Departamento de Agricultura de Estados Unidos, para el 2030 el $80 \%$ de los alimentos vendrán del exterior". Soberanía y Seguridad Alimentaria. Alianza por la Salud Alimentaria, en: http://alianzasalud.org.mx/seguridadalimentaria/

47 "En Argentina, por ejemplo, donde se ha podido medir el efecto de este fenómeno, se ha creado el colectivo "Médicos de Pueblos Fumigados", que han hecho investigaciones en La Pampa y han detectado que en los pueblos rodeados de sojales fumigados, los índices de cáncer son cuatro a siete veces superiores a la media nacional. En Yucatán, los mayas han comprobado que los cultivos transgénicos de Soja o soya afectan gravemente el ciclo vital de las abejas que producen la miel de la cual las comunidades viven" 47 R. ZIBECHI, Latiendo Resistencia. Mundos Nuevos y Guerras de Despojo, El Rebozo, Oaxaca. 2015. 
interesan. Es así como La empresa extractiva no es un actor solo económico, sino que es un actor político, social, cultural y por supuesto, también económico. ${ }^{48}$ De modo que el extractivismo va de la mano de lo que el filósofo italiano Giorgio Agamben, denomina "Estado de excepción permanente". ${ }^{49}$ La hipótesis central de Agamben es que "la declaración del estado de excepción ha sido sustituida de forma progresiva por una generalización sin precedentes del paradigma de la seguridad como técnica habitual de gobierno...o paradigma constitutivo del orden jurídico. El cual ya desde la Primera Guerra Mundial habría sustituido la excepcionalidad de la situación militar por la económica. Donde dicho estado de excepción constituye una tierra de nadie entre el Derecho público y el hecho político y entre el orden jurídico y la vida". 50 Entonces, allí donde se instala el modelo extractivo, las leyes y las protecciones legales a las poblaciones desaparecen. Así se aprecia claramente que dicho "Estado de excepción permanente" descrito por Agamben es parte integral del modelo extractivo. ${ }^{51}$ De manera que es necesario establecer posibles nexos y vínculos entre el "modelo" extractivo y algunas "anomalías" que se dan en los gobiernos tanto de la región Iberoamericana como de otros lugares del mundo. ${ }^{5253}$ Dicho de otro modo, ¿por qué los gobiernos actúan casi de la misma manera que las empresas transnacionales? ¿Por qué con demasiada frecuencia vulneran instituciones públicas o pasan por encima de ellas? es evidente entonces que estamos frente a lo que podríamos llamar una "cultura política" extractiva, que se ha ido infiltrando en todos los aspectos de las sociedades y los gobiernos. Más aún: ¿Qué relación hay entre el modelo extractivo y la gran expansión moderna del consumismo? Tal parece entonces que estamos ante una práctica

\footnotetext{
48. R. ZIBECHI, Op. Cit.

49 G. AGAMBEN, "El Estado de excepción es hoy la norma", El País, 3 de febrero de 2004. http://elpais.com/diario/2004/02/03/cultura/1075762801_850215.html

50 G. AGAMBEN, 2003. Estado de Excepción, Homo Sacer, II, I, Adriana Hidalgo Editora, Buenos Aires, Argentina.

${ }^{51}$ Quizá la particularidad y la paradoja de Iberoamérica en los últimos 10 o 15 años sea que este modelo extractivo, caracterizado por la "acumulación por despojo", ha sido encabezada en muchos casos por gobiernos de corte "progresista". Dicha particularidad, consistente en que el modelo extractivo lo encabecen los gobiernos progresistas ha sido un shock para los pueblos oprimidos de Iberoamérica porque no lo esperaban y porque vino acompañado de un discurso descolonizador como el Sumaj Qamaña, "el Buen Vivir", que en no pocos casos ha hecho lo mismo que antes, en lo que bien podríamos caracterizar como un pluralismo instrumental.

52 Por ejemplo, ¿qué relación hay entre extractivismo y corrupción? ¿No actúan también los llamados "gobiernos progresistas" al modo extractivo? $Y$ dado que alguna evidencia empírica señala que la cultura extractiva ha sido asumida en todos los escalones de los aparatos estatales. ¿Qué relación hay entonces entre instituciones débiles y vulneradas, regresiones autoritarias que se creían superadas y el modelo extractivo?

53 Para una visión desde El Ecuador, véase a SAGAL y HERNÁNDEZ, "Geopolítica del neoextractivismo: espacialidad estatal y clasificación de la resistencia en el sureste de Ecuador". 2016.
} 
"nueva" del capitalismo en su etapa "financierista", donde el extractivismo es parte destacada, pues combina ésta expansión exponencial del consumismo, con una masa de jóvenes y adultos que no tienen empleo, o tienen uno de ínfima calidad, donde parece que incluso el extractivismo promueve este tipo de empleo. ${ }^{54}$

En suma, no parece haber alternativas al extractivismo en tanto la única salida posible sea la exportación de commodities para la industria extranjera. Se sigue entonces que el extractivismo es algo que no solo sucede en las minas a cielo abierto o en los cultivos de soya transgénica, sino que estamos permeados del extractivismo. Finalmente, habrá que apuntar brevemente que no se sale del extractivismo sin crisis, que puede pasar por la reconfiguración del estado-nación actual. ${ }^{55}$ Así pues hace falta indagar sobre el papel que jugará el Derecho en dicha posible reconfiguración del Estado-nación. Reflexionar y discutir colectivamente porque el extractivismo ha infiltrado universidades, think tanks, partidos y sindicatos. Más aún: hoy tal parece que en muchos logares del mundo tener un cargo

54 Así también por ejemplo, los bonos, las "bolsas familia" o las políticas sociales asistencialistas, vienen a tapar los agujeros que el modelo extractivo implanta. En el modelo fabril los trabajadores y sus familias llegaban de las áreas rurales, comenzaban como peones a trabajar en la industria o en la construcción y a lo largo de una vida terminaban como obreros calificados y sus hijos en sus estudios secundarios y en la universidad. Era un modelo de integración y naturalmente estar en la fábrica o en el trabajo daba Derecho a la vivienda, a la educación y a la salud. Hoy en día desaparecieron todos esos Derechos y solamente hay "beneficios" que no son constitucionales. Parece ser el caso del Brasil contemporáneo, pero desde luego que no es el único. Políticas sociales como el "Plan Bolsa Familia", que llegaba en tiempos del "lulismo" (del Presidente Lula da Silva) a 50 millones de brasileños, no era producto de una ley, sino es un beneficio que le daba el gobierno a las familias. Un beneficio tramposo, porque se ingresa en el banco todos los meses y por tener esa cuenta también se puede tener tarjeta de crédito. Entonces, las familias compran y consumen, y los gobiernos fomentan eso. $Y$ al cabo del ciclo político del PT (Partido de los Trabajadores), esas familias estaban endeudadas, tanto que el $48 \%$ de los ingresos de las familias brasileñas eran para pagar deudas ¿Qué compraban?: televisor de plasma, motos, coches, lo que sea, estaban endeudados y no habían modificado su situación. Seguían siendo vendedores ambulantes o trabajadores precarios, pero metidos al sistema financiero y con créditos al consumo que los endeudan en condiciones muy desventajosas por años (R. ZIBECHI, op cit.).

55 Silvia Rivera Cusicanqui, socióloga, historiadora y activista política en las comunidades quechua y Aymara, explica que "el Estado-Nación es una camisa de fuerza para los movimientos indígenas". Es más, sostiene: "el Estado-Nación es una camisa de fuerza para las luchas sociales" (S. RIVERA, "Etnicidad estratégica, nación y neo colonialismo en América Latina", Revista Alternativa No 5. Primer semestre. 2016. Recuperado en: http://ppct.caicyt.gov.ar/index.php/alternativa/article/viewFile/9444/pdf. Sostiene dicha autora que es necesario que repensemos al Estado como horizonte emancipatorio, donde reflexionar y discutir colectivamente porque, si algo nos hace falta hoy es debatir, y vaya si el extractivismo ha infiltrado universidades, partidos y sindicatos, donde hoy parece que tener un cargo público, es tener las manos libres para 'extraer', puesto que la corrupción es parte importante del modelo extractivo. 
público, es tener las manos libres para 'extraer', puesto que la corrupción es parte muy importante del modelo extractivo. ${ }^{56}$

Expuesto lo anterior, y para empezar a llamar a las cosas por su nombre, sería pertinente preguntarnos si los proyectos denominados "de desarrollo"57 son ciertamente tales, porque se tiende a dar por sentado que los denominados "mega proyectos" de inversión traerán en automático el desarrollo a las regiones donde se implantan y que son expresiones individuales o aisladas, casuísticas, aunque cierta evidencia como la recogida por el Atlas de Justicia Ambiental de Martínez Alier en la Universidad Autónoma de Barcelona puede demostrar que no necesariamente es así. De manera que los proyectos de inversión suelen insertarse en una lógica del modelo económico y político dominante en el contexto de un sistema de apropiación privada, donde el discurso imperante preconiza que se conseguiría progreso y bienestar de manera lineal, donde dominan ideas como "productividad", "crecimiento", "competitividad" o "progreso" como los imaginarios ideales del desarrollo. Por eso en Iberoamérica y cada vez más en otras regiones del mundo, la expansión del poder privado es muy agresiva, pues los estados no limitan, sino que por el contrario, promueven y respaldan e incluso se asocian con los grandes proyectos de inversión privados. ${ }^{58}$ México es también en eso un desafortunado caso paradigmático, ${ }^{59}$ pues es uno de los países que ha firmado más Tratados de libre comercio en el mundo, así que las trasnacionales llegan a invertir con un marco

56 Por ejemplo, las mediciones sobre la percepción de la corrupción que realiza anualmente Transparency International o Transparencia Internacional, sitúan a México en el último lugar de los 34 países de la OCDE, es decir, como el más corrupto de 34. Por su parte, el Informe del Latinobarómetro 2016, visible en http: //www.latinobarometro.org/latNewsShow.jsp, concluye que: "Sin guerras, América Latina acusa violencia, corrupción y la desigualdad como los fenómenos más potentes que retienen a la democracia".

57 "Un proyecto de desarrollo es un "proceso de inversión de capital público y/o privado, nacional o internacional, para la creación o mejora de la infraestructura física de una región determinada, la transformación a largo plazo de las actividades productivas con los correspondientes cambios en el uso de la tierra y los derechos de propiedad de la misma, la explotación a gran escala de los recursos naturales, incluidos los recursos del subsuelo, y la construcción de centros urbanos, fábricas, instalaciones mineras, centrales energéticas, complejos turísticos, instalaciones portuarias, bases militares y empresas similares". R. STAVENHAGEN, Informe del relator especial sobre la situación de los derechos humanos y las libertades fundamentales de los indígenas, 21 de enero de 2003, párrafo 6. En: S.G. RUIZ, "Consulta y Consentimiento: Caso Saramaka vs. Surinam". IIJ-UNAM. 2014.

58 "Todos los extractivismos sudamericanos ocurren bajo regímenes políticos formalmente democráticos. Pero para imponer esos proyectos es necesario redefinir la democracia". Diálogo con Eduardo Gudynas en Radio Universidad Chile, en: http://radio.uchile.cl/.../eduardo-gudynas-los-gobiernos-sud.../

59 México ha celebrado 12 Tratados de Libre Comercio con 46 países, 32 Acuerdos para la "Protección Recíproca de Inversiones" con 33 países y 9 Acuerdos de Alcance limitado. Secretaría de Economía, http://www.gob.mx/se/acciones-yprogramas/comercio-exterior-paises-con-tratados-y-acuerdos-firmados-conmexico. 
jurídico creado ad- hoc para su protección, tal es el caso concreto de las multinacionales mineras, por ejemplo. ${ }^{60} \mathrm{Y}$ sin embargo, esto no ha repercutido, desde 1994 en el desarrollo nacional, siendo dicha fecha en que se firmó el Tratado de Libre Comercio de América del Norte (TLCAN) con Estados Unidos de América y Canadá, si se atiende al hecho de que más del $50 \%$ de la población mexicana vive aún en 2018 bajo la línea de pobreza según las propias estimaciones oficiales. ${ }^{61}$ Entonces, hace por lo menos 30 años se gestó el cambio del modelo de acumulación y el control y extracción de recursos naturales, lo que nos demuestra ese citado paso del llamado "Consenso de Washington" al "consenso de las commodities", que es el papel claramente asignado en el sistema-mundo a los países del sur global. Los países del norte desplazan la obtención de estos insumos (commodities) necesarios para su proceso industrial a los países del sur, así como también los costos ambientales y sociales del extractivismo. Pero tal vez debiéramos llamarle mejor "neoextractivismo", pues se produce ahora no solo una explotación, sino una sobre-explotación de los recursos naturales al tiempo que las multinacionales se expanden hacia nuevos territorios. De modo que los privados foráneos y locales no se contentan ya con participar ampliamente en la minería y el petróleo, sino que abarcan ahora la explotación forestal, las concesiones de aguas y saneamiento, la construcción y explotación de carreteras, los agro-negocios de monocultivo, la mega inversión turística, los parques eólicos (vendidos al público como energía verde), la urbanización descontrolada, o las grandes represas; todos proyectos financiados por la gran banca internacional. Es así entonces que la expansión del modelo extractivo dominante tiende a reproducir el capital y a reinvertir el excedente, que son en suma grandes proyectos, "megaproyectos de desarrollo" exógenos, que no resuelven ni preguntan sobre los problemas de las sociedades allá donde se implantan. De allí que sea tan difícil frenarlos aunque sean altamente nocivos y contaminantes y a pesar de que en muchos casos no cuentan con la anuencia de los pueblos y comunidades afectadas, especialmente cuando éstas son indígenas, en lo que también es calificado por algunos especialistas como un "racismo ambiental". ${ }^{62} \mathrm{~A}$ esto debemos

60 En México las empresas mineras de capital extranjero y también nacional, tienen concesiones que equivalen ya al $20 \%$ del territorio del país, con un marco jurídico reformado y especialmente diseñado para facilitar su implantación a costes de operación muy bajos.

61 Según CONEVAL (Consejo Nacional de Evaluación de la Política de Desarrollo Social) en México hay 53.2 millones de mexicanos con ingreso inferior a "la línea de bienestar".

62 La definición del concepto es enunciada por Michael K. Dorsey: "...mayor presencia de residuos contaminantes en lugares habitados por minorías no blancas; la preferencia de las industrias por desechar sus residuos cerca a estas comunidades; y la acción discriminatoria del estado al ser más estricto en cuanto a sanciones y reparaciones cuando la contaminación se produce en comunidades 
añadir la intensidad temporal y territorial de las "tomas" del espacio y el territorio, pues sin banca internacional y Estado que los respalden, no hay mega-negocios posibles. Es entonces el propio Estado el que facilita el aterrizaje de estos "mega" proyectos, donde los impactos producidos desatan grandes transformaciones sociales que en muchas regiones pueden ser irreversibles, pues son dinámicas exógenas a las comunidades y a sus diferentes y diversas vocaciones, con decisiones a menudo tomadas a miles de kilómetros del teatro real de las inversiones y del asiento físico de las comunidades locales. Las decisiones de inversión en megaproyectos son generalmente vinculadas a las ideas de la demanda, tecnocráticas y centralistas y por tanto, esencialmente autoritarias. Esa es la lógica imperante y el modus operandi de privados y gobiernos. ${ }^{63}$ Todo esto implica un serio riesgo para la propia existencia de los pueblos indígenas y de su cultura, pues se acaba con el medio ambiente sano64, con los recursos naturales y con ello, con las lenguas originarias y la diversidad cultural de una sociedad en aras de un progreso nada claro hasta la fecha. Así es como los pueblos indígenas han desarrollado modelos alternativos de vida, por lo que siendo México un país megadiverso en lo étnico y en lo biológico, ${ }^{65}$ los recursos naturales hoy en disputa también tendrán que ser muy diversos. En estos casos, todos los Derechos Fundamentales protegidos por el Derecho internacional quedan vulnerados de una u otra manera. Por esos son importantes precedentes como la sentencia en el caso Awas Tingi vs Nicaragua, pues da al territorio una dimensión antes no concedida en lo concerniente a la supervivencia de los pueblos indígenas basada en el territorio. En esa constante tensión entre poblaciones indígenas, territorios y apropiación privada, La Corte IDH ha sentenciado, en el caso Yake $A x a^{66}$ por ejemplo, que en algunos casos puede ser necesario que la sociedad, a través de un Estado observante de los

blancas que en comunidad negras, hispanas o judías", M. K. DORSEY, "Race, Poverty and Enviroment", 22 Legal Stud. F. 501 (1998), recuperado en: heinoline.org

63 Cuando se trata de hablar de trasvase ilegal de agua entre cuencas, la construcción de represas y de decisiones autoritarias que vulneran claramente los principios de libre determinación y consulta previa que afectan a colectivos humanos e indígenas, el caso de la tribu Yaqui de Sonora, en el noroeste de México, es paradigmático porque refleja claramente el razonamiento ideológico que subyace en el extractivismo: "¿Qué puede saber y que puede decir un puñado de indios sobre lo que los técnicos y expertos patrocinados por empresas y gobiernos locales y foráneos ya decidieron de antemano a miles de kilómetros de distancia?"

${ }^{64}$ En el caso mexicano, el Derecho al Medio Ambiente sano está elevado también a la categoría de Derecho Fundamental según el artículo $4^{\circ}$ Constitucional vigente.

65 Según información oficial en México existen 66-68 grupos étnicos originarios, que hablan más de 360 variantes lingüísticas; mientras que la diversidad biológica de México está considerada entre las primeras cinco del mundo; por lo que no es casual que el fenómeno extractivista se recrudezca en todo el territorio.

${ }^{66}$ Es una sentencia de la Corte IDH de 2005 contra el estado paraguayo, véase: http://www.corteidh.or.cr/docs/casos/articulos/seriec_125_esp.pdf 
Derechos Fundamentales de los pueblos indígenas, restrinja cierto tipo de propiedad del alcance de los privados.

\section{6.- CONSULTA Y CONSENTIMIENTO}

Aún a pesar del entorno económico, político y social descritos, los procesos de consulta a los pueblos indígenas son, se insiste, una obligación internacional de los Estados y no una facultad potestativa, ello de acuerdo con las disposiciones del Convenio 169 OIT sobre pueblos indígenas y Tribales y la Declaración de la ONU sobre Pueblos indígenas de 2007. Sin embargo, estos procesos afrontan limitaciones frecuentes, como la falta de claridad conceptual y consensos sobre quiénes y cómo ostentan la representación de los pueblos indígenas; ante los cuales, los Órganos del Sistema Interamericano de Derechos Humanos (SIDH) han hecho informes temáticos y vistas in loco, 0 bien emitido sentencias tanto para evaluar situaciones en particular como para contribuir a la garantía de esos Derechos individuales y colectivos indígenas con base en estándares internacionales. Dicha situación afecta solo en Iberoamérica a 642 pueblos indígenas y a entre 30 y 50 millones de habitantes ${ }^{67}$ que siguen siendo objeto de discriminación cotidiana debido a sus diferencias étnicas y culturales, pese a los recientes reconocimientos constitucionales del carácter multicultural de la mayor parte de los estados Iberoamericanos, que son en su mayoría de reciente data. No obstante, persiste una evidente brecha en la implementación de estos Derechos que no refleja cabalmente los avances a nivel legal y jurisprudencial. Entonces, hay que tener cuidado con pensar que con el marco vigente del Derecho Internacional, con la existencia del Convenio 169 de la OIT o con la Declaración de la ONU sobe los Derechos de los Pueblos Indígenas de 2007 y su análoga americana de 2017, los problemas quedaron resueltos de una vez y para siempre. ${ }^{68}$ Evidentemente que el marco internacional expuesto es un avance y también es mejor que nada, pero lejos está de ser la panacea, porque tal parece a la luz de la casuística imperante que llega a los foros internacionales, que el Derecho a la consulta parece ideado no para los pueblos indígenas a los que pretende proteger, sino para que los Estados y las empresas justifiquen haber reunido ciertos requisitos previos a su apropiación y explotación-extracción de territorios y regiones enteras. Así, por ejemplo, consulta no es igual a veto, pues los pueblos indígenas no pueden vetar un proyecto "de desarrollo". Esto se aprecia de modo claro en el sonado caso de Belo

67 ONU-DH, Indigenous peoples:www.un.org/development/desa/indigenouspeoples/ 68 Véase al respecto a: B.CLAVERO, "El difícil Reto de la Declaración Americana sobre Derechos de los Pueblos Indígenas". 2016. Recuperado en:

http://www.bartolomeclavero.net/?p=713 
Monte en Brasil, 69 y es por eso que la interpretación evolutiva del artículo 19 del convenio 169 OIT, introduce la idea de un consentimiento que sea previo, libre, informado, de buena fe y culturalmente adecuado. La Corte IDH sostiene, como se explica en los casos expuestos más adelante, que se debe obtener el consentimiento de forma obligatoria, sobre todo cuando hay desplazamiento, cuando se entierran residuos peligrosos o cuando el plan de desarrollo a ejecutar afecta a la tierra y a los territorios. Se deja sentado así que hay un vínculo indisoluble entre consulta y consentimiento que no siempre se consigue en la práctica gubernamental. $Y$ en los peores casos ni siquiera se intenta, como queda de manifiesto, por ejemplo, en el caso Yaqui en México, ${ }^{70}$ y que desde luego no es el único, sino que forma parte de un claro patrón extractivo en los términos que se ha venido explicando. Entonces, se concluye de lo expuesto que el Derecho Fundamental de los pueblos originario en el caso de los denominados "mega proyectos", es a la Consulta Previa e informada en términos del convenio 189 de la OIT, suscrito en 1989. Pero no cualquier consulta, sino una que satisfaga los siguientes requisitos:

a) Consulta a los pueblos originarios a través de sus métodos y Autoridades Tradicionales.

b) Consulta con el fin de llegar a un acuerdo u obtener el consentimiento informado del pueblo originario.

Del mismo modo, el artículo 16.2 habla del traslado de sus territorios solo con el consentimiento expreso del pueblo afectado. La Declaración de la ONU de 2007 lo establece, así como estatuye la cooperación de buena fe por parte del Estado para obtener el consentimiento libre e informado de los pueblos originarios. Si los proyectos de desarrollo afectan territorio y tierras del pueblo originario, entonces deberá recabarse antes de la realización del proyecto el consentimiento previo. Así mismo, el artículo 29.2 dispone que los Estados adoptarán medidas para evitar riesgos a la integridad o salud de los miembros de los pueblos originarios. Dice la Sentencia de la Corte en un precedente fundamental derivado del caso Saramaka versus Surinam, ${ }^{71}$ que la consulta no puede ser entendida como un acto, sino que consiste en varios, como por ejemplo, en dar aviso temprano de la intención del proyecto a la comunidad para darle tiempo a deliberar. Entonces, tenemos que el consentimiento debe ser libre, informado y previo para ser válido. Y

69 Véase por ejemplo a: L. M. UHARTE, "El Megaproyecto Hidroeléctrico de Belo Monte en Brasil: Impactos Múltiples". Revista de Antropología Experimental no 16, Texto7: 91-107. 2016. Universidad de Jaén, España. Recuperado en: https://revistaselectronicas.ujaen.es/index.php/rae/article/viewFile/2640/2501 ${ }^{70}$ E. PASILLAS, Op. Cit.

71 Corte Interamericana de Derechos Humanos, 2007. Caso del Pueblo Saramaka vs. Surinam. Sentencia del 28 de noviembre de 2007. (Excepciones Preliminares, Fondo, Reparaciones y Costas).

http://www.corteidh.or.cr/docs/casos/articulos/seriec_172_esp.pdf 
también, que no cualquier consulta, hecha de cualquier modo, es válida. Ésta interpretación constituye un salto cuantitativo en relación con los requisitos formales de la consulta. Así también, la Corte IDH ha establecido que el Derecho a la Identidad es un Derecho Fundamental, de modo que en una sociedad multicultural, plural y democrática, el Estado debe garantizar a los pueblos originarios que su Derecho a la Consulta Previa, libre informada, de Buena Fe, y con objeto de obtener su consentimiento sea cabalmente respetado. ${ }^{72}$

\section{7.- LA JURISPRUDENCIA DE LA CORTE INTERAMERICANA DE DERECHOS HUMANOS EN MATERIA INDÍGENA}

La Corte Interamericana de Derechos Humanos (en adelante Corte IDH) se instituyó en 1969 como parte de la Convención Americana sobre Derechos Humanos ${ }^{73}$ (capítulo VII de la parte II), pero entró en funciones hasta 18 de julio de 1978, debido a que hasta entonces se reunió el número de países establecido por el instrumento para el inicio de su vigencia, fallando su primer caso en hasta 1988. Desde ese momento, se produjo el proceso de establecimiento de una estructura judicial que tiene como misión principal hacer eficaces los Derechos Humanos en el continente. Así, la Corte IDH tiene dos funciones específicas en el sistema regional de Derechos Humanos: primero, una función jurisdiccional, a través de la cual evalúa la responsabilidad de los Estados respecto a situaciones que sean planteadas como infracciones a la Convención Americana de Derechos Humanos. La otra función es la Consultiva, la cual ejerce según lo dispuesto en el artículo 64 (1). ${ }^{74}$ Luego, hay que apuntar 72 Recientemente, hay avances en este sentido en las Cortes Supremas de algunos
países de Iberoamérica. Guatemala, por ejemplo, en el caso: Consejo de Principales
de Trapichito, Sumal Chiquito y Nuevo Amanecer Nebaj (septiembre de 2015).
También en Chile en 2014 , con el proyecto de El Morro y el Parque Eólico de Chiloé.
El 7 de octubre de 2014 , La Corte Suprema de Chile revocó un fallo de la Corte de
Apelación de Copiapó que rechazó un recurso de las comunidades indígenas
afectadas por un mega proyecto minero de la empresa Gold Corp canadiense. El
Máximo Tribunal ordenó un proceso de Consulta de acuerdo con el Convenio 169 de
la OIT. En el caso de Chiloé, La Corte revocó la aprobación ambiental de un parque
eólico de la multinacional sueca Econopower, que no consultó previamente a la
Comunidad indígena Antolafaqué. También en Argentina, en 2014 , cono los casos
de Chubut y El Chaco. La Corte Suprema anuló la sentencia de un tribunal de
Chubut y lo instó a aplicar El Derecho indígena en una disputa territorial entre una
comunidad mapuche y un privado. La Corte remarcó así la vigencia de del Convenio
169 de la OIT, norma que se entiende que es supra legal y que protege a los
pueblos originarios.
73 O Pacto de San José. San José de Costa Rica, 7 al 22 de noviembre de 1969.
https://www.oas.org/dil/esp/tratados_b-
32 convencion_americana_sobre_derechos_humanos.htm
74 "Los Estados miembros de la Organización podrán consultar a la Corte acerca de
la interpretación de esta Convención o de otros tratados concernientes a la
protección de los derechos humanos en los Estados Americanos. Asimismo, podrán
consultarla, en lo que les compete a los órganos enumerados en el capítulo X de la 
que aunque la Convención Americana de Derechos Humanos tiene como referente fundamental lo que denomina la persona humana entendida como el sujeto individualmente considerado, ${ }^{75}$ la Corte IDH ha expresado que ésta no es la única que tiene Derechos Humanos, sino que existen realidades étnicas como las de los pueblos indígenas, que son titulares de derechos específicos. Entonces, en el contexto descrito, para la Corte Interamericana los pueblos indígenas son estructuras socioculturales que poseen derechos como colectivos de orden político, económico, cultural y territorial que deben ser garantizados y respetados por los Estados. ${ }^{76}$ Entonces, como se verá en los casos expuestos, es la propia lucha de los pueblos indígenas contra la asimilación y la integración a la sociedad blanca o mestiza mayoritaria la que marca la evolución de la jurisprudencia de la Corte Interamericana de Derechos Humanos (Corte IDH) que, en ausencia previa de un texto específico, ha venido fortaleciendo los alcances de la Convención Americana de Derechos Humanos (la Convención) para hacer posible el goce efectivo de los Derechos Humanos en condiciones de una igualdad que debe ser real y no solo formal. ${ }^{77}$ Así, desde el punto de vista de la jurisprudencia del Sistema interamericano de Derechos Humanos, hay algunos casos paradigmáticos relacionados con los Derechos Fundamentales de los pueblos indígenas en lo que parece ser un patrón continental que tienen que ver con el Derecho a la Consulta en los llamados "proyectos de desarrollo" o "mega proyectos de desarrollo" de los que ya se ha explicado su caracterización general, cuya idea central es ilustrar la jurisprudencia fijada y aplicada por la Corte en algunos de los casos sometidos a su jurisdicción por los propios pueblos indígenas del continente, ante una tendencia repetida prácticamente

Carta de la Organización de los Estados Americanos, reformada por el Protocolo de Buenos Aires". Convención Americana sobre los Derechos Humanos, 1969. artículo 64, suscrita en San José de Costa Rica el 22 de noviembre de 1969, en la Conferencia Especializada Interamericana Sobre Derechos Humanos.

75 "Toda persona tiene derecho a...". Sin embargo, los pueblos indígenas han reivindicado con ahínco ante los organismos internacionales y los Estados que son sujetos colectivos portadores de derechos y no asociaciones de personas o un colectivo de personas, como lo quiere decimonónicamente el Estado-nación de corte liberal.

76 J.D. CASTRILLÓN, "La Corte Interamericana de Derechos Humanos y los derechos de los pueblos indígenas", en Becerra Ramírez, Manuel (coord.), La Corte Interamericana de Derechos Humanos a veinticinco años de su funcionamiento, México, UNAM, Instituto de Investigaciones Jurídicas, 2007. pp. 143-204, http://biblio.juridicas.unam.mx/libros/5/2496/10.pdf .Consultado el 22 de abril de 2017.

77 Adicionalmente a lo anterior, en Iberoamérica durante el tiempo de funcionamiento de la Corte IDH se han dado diversos procesos de reforma constitucional en países como: Nicaragua, 1985; Colombia, 1991; Paraguay, 1992; Perú, 1993; Bolivia, 1995 y Ecuador, 1998. Además de la reforma constitucional en Argentina en 1994, la Constitución Bolivariana en Venezuela en el 2000 y la reforma mexicana de 2001. En todas ellas los pueblos indígenas ya fueron reconocidos como sujetos específicos de derechos (CASTRILLÓN, Óp. Cit. Pág.149).

Universitas, 2019, $\mathrm{N}^{\circ} 29 /$ pp. 2-31 
en todos los países con poblaciones indígenas, donde se violan al incumplir de uno u otro modo la normativa internacional que los protege de un modo específico. Sin duda destaca con su actuación la Corte IDH, pues sentó las bases de un método de interpretación universal de muy largo alcance en el marco de su función consultiva [OC-1/1982]. En materia contenciosa, la jurisprudencia interamericana está marcada por la apertura hacia fuentes externas al sistema con fines de interpretación de la Convención. Así, el universalismo jurídico del juez interamericano tiene fundamentos convencionales precisos: el artículo 1-1 consagra la obligación estatal de respetar y garantizar los derechos convencionales, el artículo 2 establece el deber estatal de adecuar el derecho interno y el artículo 29 prohíbe expresamente una interpretación restrictiva de los derechos convencionales estableciendo la superioridad del principio pro homine ${ }^{78}$ (pro personae o favor libertatis) ${ }^{79}$. Para futuro papel de trabajo queda exponer los temas jurisprudenciales más destacados en algunas decisiones paradigmáticas y su significado para el surgimiento de los derechos de los pueblos indígenas en el sistema interamericano, haciendo énfasis en las razones por las cuales los casos presentados muestran el contexto global en el que se desenvuelven actualmente las reivindicaciones indígenas en el continente; quedando de manifiesto que los hechos evaluados en cada una de las decisiones de la Corte IDH destacan la interacción de los pueblos indígenas con los Estados-nación y también con los diferentes actores económicos locales, nacionales y trasnacionales.

\section{8.- REFERENCIAS}

78 El principio pro persona o pro personae parece haber sido definido por primera vez por el juez Rodolfo E. Piza Escalante en uno de sus votos adjuntos a una decisión de la Corte IDH. En dicha ocasión, el juez Piza afirmó que el principio pro persona es [Un] criterio fundamental [que] [...] impone la naturaleza misma de los derechos humanos, la cual obliga a interpretar extensivamente las normas que los consagran o amplían y restrictivamente las que los limitan o restringen. [De esta forma, el principio pro persona] [...] conduce a la conclusión de que [la] exigibilidad inmediata e incondicional [de los derechos humanos] es la regla y su condicionamiento es la excepción. Opinión Separada del juez Rodolfo E. Piza Escalante", en Corte IDH, Exigibilidad del Derecho de Rectificación o Respuesta (arts. 14.1, 1.1 y 2 Convención Americana sobre Derechos Humanos), Opinión Consultiva oc-7/86 del 29 de agosto de 1986, serie A, núm. 7, párr. 36 (X. MEDELLÍN, Principio pro Persona 1. Coedición: Suprema Corte de Justicia de la Nación (SCJN), Oficina en México del Alto Comisionado de las Naciones Unidas para los Derechos Humanos (oacnudh) y Comisión de Derechos Humanos del Distrito Federal (cdhdf) México. 2013.

79 Para una explicación amplia del método universal de interpretación aplicado a los pueblos indígenas y tribales, por la Corte IDH véase a R. ESTUPIÑAN-SILVA, "Pueblos indígenas y tribales: la construcción de contenidos culturales inherentes en la jurisprudencia interamericana de derechos humanos." 2014. 
A. ESCOBAR, "Más allá del desarrollo: postdesarrollo y transiciones hacia el pluriverso", Revista de Antropología Social, 2012, 21 pp. 23-62, 2012. Recuperado en:

https://revistas.ucm.es/index.php/RASO/article/viewFile/40049/3847 9

A. VÁSQUEZ (comp) Extractivismo urbano, Debates para una construcción Colectiva de Ciudades, Colección Chico Mendes, Editorial El Colectivo, CEAPI-Fundación Rosa de Luxemburgo, Buenos Aires. 2017.

AAVV. 2016. México: Empresas y Derechos Humanos. Visita a México del Grupo de Trabajo sobre Empresas y DDHH. Compendio de información que presentan la Coalición de Organizaciones de la Sociedad Civil al Grupo de Trabajo sobre Empresas y Derechos Humanos de la ONU. 29 de agosto. Recuperado en:

http://www.prodesc.org.mx/index.php/es/2014-04-21-22-18-

02/relacionados/592-mexico-empresas-y-derechos-humanos

A. ACOSTA, "Extractivismo y neoextractivismo, dos caras de la misma maldición", 25 de julio. 2012. Recuperado en: ecoportal.net.

B. CLAVERO, "El difícil reto de la Declaración Americana sobre Derechos de los Pueblos Indígenas". 2016. Recuperado en: http://www. bartolomeclavero. net/?p=713

B. SANTOS, Pensar el Estado y La Sociedad: Desafíos actuales, CLACSO coediciones, Waldhuter Editores, Buenos Aires, 2009.

B. SANTOS, "Las venas abiertas de Nicaragua", La Jornada, 7 de julio de 2018.

CONSEJO NACIONAL DE EVALUACIÓN DE LA POLÍTICA SOCIAL (CONEVAL). La Pobreza en la población Indígena de México 2012. Recuperado en:

https://www.coneval.org.mx/Informes/Coordinacion/INFORMES_Y_P UBLICACIONES_PDF/POBREZA_POBLACION_INDIGENA_2012.pdf

D. CADEMARTORI. Inversión extranjera en el desarrollo de la región minera de Antofagasta (Chile): historia y perspectivas, Edición electrónica gratuita. Pp. 21-23. 2010. Texto completo en: www.eumed.net/libros/2010b/677/

E. PASILLAS, "Multiculturalismo y derechos fundamentales en el noroeste de México: El caso de la tribu yaqui", Estudios Fronterizos, Vol.19, 2018. Recuperado en:

http://ref.uabc.mx/ojs/index.php/ref/article/view/658

F. ESCALANTE, Historia Mínima del Neoliberalismo, El Colegio de México, México. 2015.

F. LÓPEZ. iLa tierra no se vende!, Las tierras y los territorios de los pueblos indígenas de México, Centro de Orientación y Asesoría a Pueblos indígenas, Tosepan, Instituto Mexicano de Desarrollo Comunitario, y Centro de Estudios para el Cambio en el Campo Mexicano, México. 2015.

G. AGAMBEN, "El Estado de excepción es hoy la norma", El País, 3 de febrero de 2004. 
http://elpais.com/diario/2004/02/03/cultura/1075762801_850215.ht $\mathrm{ml}$

G. AGAMBEN, Estado de Excepción, Homo Sacer, II, I, Adriana Hidalgo Editora, Buenos Aires, Argentina. 2003.

G. GORDILLO, Seguridad y Soberanía alimentarias. Documento base para discusión. Organización de las Naciones Unidas para la Alimentación y la Agricultura, (FAO). 2013. Recuperado en:

http://www.fao.org/3/a-ax736s.pdf

E. GUDYNAS, "La ecología política de la crisis global y los límites del capitalismo benévolo", Iconos, Revista de Ciencias Sociales, No 36, Quito, enero de 2010.

H. GONZÁLEZ, "Las redes transnacionales y las cadenas globales de mercancías: la agricultura de exportación en México", Amérique Latine Histoire et Mémoire. Les Cahiers ALHIM [En línea], 2|2001, Publicado el 13 enero 2006, consultado el 19 mayo 2018. URL: http://journals.openedition.org/alhim/613

I. WALLERSTEIN, "El Multiculturalismo y sus Dilemas", La Jornada, 22 de febrero. 2015. Recuperado en: http://www.jornada.unam.mx/2015/02/22/opinion/022a1mun

J. CASTRILLÓN, "La Corte Interamericana de Derechos Humanos y los derechos de los pueblos indígenas", en Becerra Ramírez, Manuel (coord.), La Corte Interamericana de Derechos Humanos a veinticinco años de su funcionamiento, México, UNAM, Instituto de Investigaciones Jurídicas, 2007. pp. 143-204, http://biblio.juridicas.unam.mx/libros/5/2496/10.pdf

J. JARAB, en Los Derechos de los Pueblos Indígenas en México, una mirada desde el Sistema de Naciones Unidas. Oficina en México del Alto Comisionado de Naciones Unidas para los Derechos Humanos. México, Primera edición. Pág. 9. 2018.

L. UHARTE, "El Megaproyecto Hidroeléctrico de Belo Monte en Brasil: Impactos Múltiples". Revista de Antropología Experimental no 16, Texto7: 91-107. 2016. Universidad de Jaén, España. Recuperado en:

https://revistaselectronicas.ujaen.es/index.php/rae/article/viewFile/2 640/2501

M. GANDARILLAS, (Ed). Extractivismo, nuevos contextos de dominación y resistencia. CEDIB. Cochabamba, Bolivia. 2014.

M. DORSEY, "Race, Poverty and Enviroment", 22 Legal Stud. F. 501.1998. Recuperado en: heinoline.org

M. SVAMPA, "Extractivismo en América Latina y el consenso de las commodities", El Correo de la Diáspora Latinoamericana. 2013. Recuperado en:

http://www.elcorreo.eu.org/Extractivismo-en-America-Latina-y-elConsenso-de-los-Commodities?lang =fr

MARTÍNEZ, J. "Ecología política del extractivismo y justicia socio- ambiental". Interdisciplina, Vol. 3, No.7, UNAM. 2015. Recuperado en: 
http://www.revistas.unam.mx/index.php/inter/article/view/52384

ONU. Declaración de la ONU sobre los Derechos de Los Pueblos indígenas. Asamblea General, 13 de septiembre de 2007. En:

http://www.un.org/esa/socdev/unpfii/documents/DRIPS_es.pdf

ONU-HR, Indigenous peoples:

www.un.org/development/desa/indigenouspeoples/

ONU. Consejo Económico y Social. Comité de Derechos Económicos, Sociales y culturales. Observación general núm. 24 (2017) sobre las obligaciones de los Estados en virtud del Pacto Internacional de Derechos Económicos, Sociales y Culturales en el contexto de las actividades empresariales. Aprobada por el Comité de Derechos Económicos, Sociales y Culturales en su $61^{\mathrm{er}}$ período de sesiones (29 de mayo a 23 de junio de 2017). Recuperado en: https://tbinternet.ohchr.org/_layouts/treatybodyexternal/TBSearch.a spx? Lang=en\&TreatyID =9\&DocTypeID =11)

P. PÉREZ, "El Gobierno autónomo Indígena de Cherán-Kéri, Michoacán, México." Revista FAIA - Programa Internacional de Investigación en Filosofía Intercultural de la Liberación. ISSN 22506810. Buenos Aires. En:

http://editorialabiertafaia.com/pifilojs/index.php/FAIA/article/view/12 9

R. ESTUPIÑAN-SILVA, "Pueblos indígenas y tribales: la construcción de contenidos culturales inherentes en la jurisprudencia interamericana de derechos humanos". Anuario mexicano de derecho internacional, 14, 581-616. 2014. Recuperado de:

http://www.scielo.org.mx/scielo.php?script=sci_arttext\&pid=S1870-

R. STAVENHAGEN, Informe del relator especial sobre la situación de los derechos humanos y las libertades fundamentales de los indígenas, 21 de enero de 2003, párrafo 6. En: S.G. RUIZ, "Consulta y Consentimiento: Caso Saramaka vs. Surinam". IIJ-UNAM. 2014.

R. ZIBECHI, Latiendo Resistencia. Mundos Nuevos y Guerras de Despojo, El Rebozo, Oaxaca, 2015.

S. RIVERA, "Etnicidad estratégica, nación y neo colonialismo en América Latina", Revista Alternativa No 5. Primer semestre. 2016. Recuperado en:

http://ppct.caicyt.gov.ar/index.php/alter-

nativa/article/viewFile/9444/pdf

L. SAGAL y HERNÁNDEZ H. "Geopolítica del neoextractivismo: espacialidad estatal y clasificación de la resistencia en el sureste de Ecuador", Pacarina del Sur, Revista de Pensamiento Crítico Latinoamericano, 20 de noviembre de 2016

http://www.pacarinadelsur.com/home/abordajes-y-contiendas/1175geopolitica-del-neoextractivismo-espacialidad-estatal-y-clasificacionde-la-resistencia-en-el-sureste-de-ecuador

T. PIKETTY, El Capital en el Siglo XXI, Fondo de Cultura Económica, México. 2015. 
TREMBLAY S. Y HÉBERT G. "¿Que es el extractivismo?" Martes 26 de febrero. 2013. Recuperado en:

http://www.conflictosmineros.net/contenidos/18internacional/12097-ique-es-extractivismo.

UNIVERSITAT AUTONOMA DE BARCELONA (UAB). EI EJAtlas alcanza los 2.100 casos de estudio de conflictos socio-ambientales en el mundo, 2017. 3 de mayo. 2017. Recuperado en:

http://www.uab.cat/web/sala-de-prensa/detalle-noticia/el-ejatlasalcanza-los-2-100-casos-de-estudio-de-conflictos-socio-ambientalesen-el-mundo-1345667994339. html?noticiaid $=1345724763308$.

V. SHIVA, Cosecha robada. El secuestro del suministro mundial de alimentos, Buenos Aires, Paidós. 2003.

V. TOLEDO. "La Crisis de la Modernidad requiere una transformación civilizatoria". Memoria, Revista de Crítica Militante. 2018. Recuperado en: https://revistamemoria.mx/?p=1239 